\title{
Value of Estimating Methylmalonic Acid Excretion in Anaemia
}

\author{
A. E. GREEN, ${ }^{*} \dagger$ M.B., M.C.PATH. ; G. D. PEGRUM,* M.D., M.R.C.P., M.C.PATH
}

Brit. med. F., 1968, 3, 591-592

\begin{abstract}
Cummary : A rapid technique suitable for routine $\checkmark$ pathology laboratories has been used to estimate methylmalonic acid excretion in a 24-hour urine collection following a $10 \mathrm{~g}$. valine load. Levels above $40 \mathrm{mg} . / 24$ hours were found only in patients with vitamin $B_{12}$ deficiency. Patients with pernicious anaemia treated more than 24 hours before urine collection and patients with other types of anaemia had methylmalonic acid levels below $25 \mathrm{mg} . / 24$ hours.
\end{abstract}

This method of demonstrating vitamin $B_{12}$ deficiency can be applied rapidly in debilitated patients so that specific treatment can be instituted within 36 hours of admission.

\section{Introduction}

It has been established that vitamin $B_{12}$ is required in the metabolism of propionic acid to succinic acid, acting as a coenzyme for the conversion of methylmalonic acid to succinic acid (White, 1962). Methylmalonic acid has been shown to be excreted in small amounts in normal urine, but to be present in excess in vitamin $B_{12}$ deficiency (Cox and White, 1962 ; Barness, Young, Mellman, Kahn, and Williams, 1963). There is an overlap between the normal and abnormal ranges, but this can be abolished by giving a valine load before collecting urine (Gompertz, Hywel Jones, and Knowles, 1967).

Methods of estimating methylmalonic acid in urine have been described using gas chromatography, which is accurate but unsuitable for use in most clinical laboratories (Cox and White, 1962) and thin-layer chromatography,. which is only semiquantitative (Bashir, Hinterberger, and Jones, 1966). The development of a colorimetric method suitable for use in a routine laboratory (Green, 1968) stimulated the present study to find whether methylmalonic acid excretion would be of value in clinical situations in which a severe megaloblastic anaemia existed.

The definitive diagnosis of megaloblastic anaemia may be lengthy, yet in some clinical situations rapid treatment with the deficient haematinic is essential. Megaloblastic anaemia is usually gradual in development and often occurs in the elderly, who are slow to complain. The problem is whether to give vitamin $B_{12}$ or folic acid therapy. Assay of blood levels of serum vitamin $B_{12}$ and folate and other diagnostic procedures are relatively slow. Intrinsic factor and intrinsic factor antibody determinations can be carried out rapidly in some centres but are not abnormal in all cases of vitamin $\mathrm{B}_{12}$ deficiency. The possible risk of provoking neurological symptoms encourages most physicians to treat the patient with vitamin $B_{12}$ before investigations are complete. When the anaemia has been due to folate deficiency we have seen the delay in response so caused to have serious consequences.

\section{Patients and Methods}

Thirty-eight patients with haemoglobin levels between 3.2 and $12.8 \mathrm{~g} . / 100 \mathrm{ml}$. have been studied. Thirty-seven were \footnotetext{
* Department of Haematology, Charing Cross Hospital Medical School,
London W.C.2.

† Now at St. Stephen's Hospital, London S.W.10.
}

admitted to hospital with symptoms of anaemia and one with neurological symptoms of subacute combined degeneration of the cord ( $\mathrm{Hb} 12.8 \mathrm{~g} . / 100 \mathrm{ml}$.). A marrow sample was aspirated ${ }^{\infty}$ from the sternum or iliac crest in each case. Thirty-one had 0 megaloblastic erythropoiesis, seven were normoblastic.

Serum vitamin $B_{12}$ levels were assayed with Lactobacillus $\vec{\omega}$ leichmannii (normal level $120-400 \mu \mu \mathrm{g} . / \mathrm{ml}$.).

Serum folic acid activity and red cell folate were assayed with $L$. casei (normal serum level 5-25 $\mu \mathrm{mg} . / \mathrm{ml}$. ; normal redo cell level $165-640 \mu \mathrm{mg} . / \mathrm{ml}$.).

Valine Loading.-All but five patients were given $10 \mathrm{~g}$. of valine dissolved in water and flavoured with fruit juice.

Collection of Urine.-Twenty-four-hour urine specimens은 were collected into bottles containing $10 \mathrm{ml}$. of concentrated $V$ hydrochloric acid as a preservative. The total volumes were $c$ ) recorded and aliquots stored at $-20^{\circ}$ C. until the estimation was carried out.

Estimation of Methylmalonic Acid-The method is described in detail elsewhere (Green, 1968). Acidified urine was saturated with ammonium sulphate and extracted with ethanol and ether, $\vec{\oplus}$ and the extract was purified with a strongly basic ion exchange $\oplus$ resin. The methylmalonic acid was eluted and a colour developed with diazotized $p$-nitroaniline.

\section{Results}

Patients with Vitamin $B_{12}$ Responsive Anaemia.-Twenty- $\bar{O}$ three patients aged 40 to 83 were studied; all had megalo- 3 blastic erythropoiesis and serum vitamin $B_{12}$ levels below $100 \mu \mu \mathrm{g} . / \mathrm{ml}$. The Schilling test was abnormal in all those patients in whom this was performed (see Table). All patients responded to vitamin $B_{12}$ therapy as shown by a rise in reticulocyte count and a significant increase in haemoglobin concentration. Each of the 15 patients whose urine was collected before treatment was started had excretion rates of $\delta$ methylmalonic acid above $50 \mathrm{mg} . / 24$ hours (range $50-320 \mathrm{mg} . /$ 24 hours). Two patients treated with vitamin $B_{12}$ immediately $ᄋ$ before receiving the valine and starting the 24-hour urine collection had levels of 63 and $45 \mathrm{mg} . / 24$ hours respectively. $\sigma$ Urine from six patients who had been given vitamin $B_{12}$ more $\frac{D}{0}$ than a day before the 24-hour urine was collected had levels below $20 \mathrm{mg} . / 24$ hours (see Chart).

Valine Loading.-Eighteen of the vitamin $B_{12}$ deficient patients received valine before collection of the 24-hour urine; five were not given valine. In 12 patients who had received 0 no therapy the excretion of methylmalonic acid in the urine 24 hours after the valine was more than $60 \mathrm{mg} . / 24$ hours? (range $60-320 \mathrm{mg} . / 24$ hours). Three untreated patients who were not given valine had levels of 50 and 100 (two cases) mg./24 hours. Valine loading in two patients immediately after vitamin $B_{12}$ treatment gave methylmalonic acid levels of $\frac{\overrightarrow{\mathbb{D}}}{\mathbb{Q}}$ 45 and $63 \mathrm{mg} . / 24$ hours. Valine was given to four patients who had been treated with vitamin $\mathrm{B}_{12}$ for more than 24 hours ; in these the excretion of methylmalonic acid was 15 and 5 음 (three cases) $\mathrm{mg} . / 24$ hours. In all the untreated cases of vitamin $B_{12}$ deficiency (15) the 24-hour excretion of methyl- $\bar{\partial}$ malonic acid was above $50 \mathrm{mg} . / 24$ hours. In the 24 hours following therapy raised levels were still obtained, but after a greater interval the excretion fell below $20 \mathrm{mg} . / 24$ hours. 
Table of Results
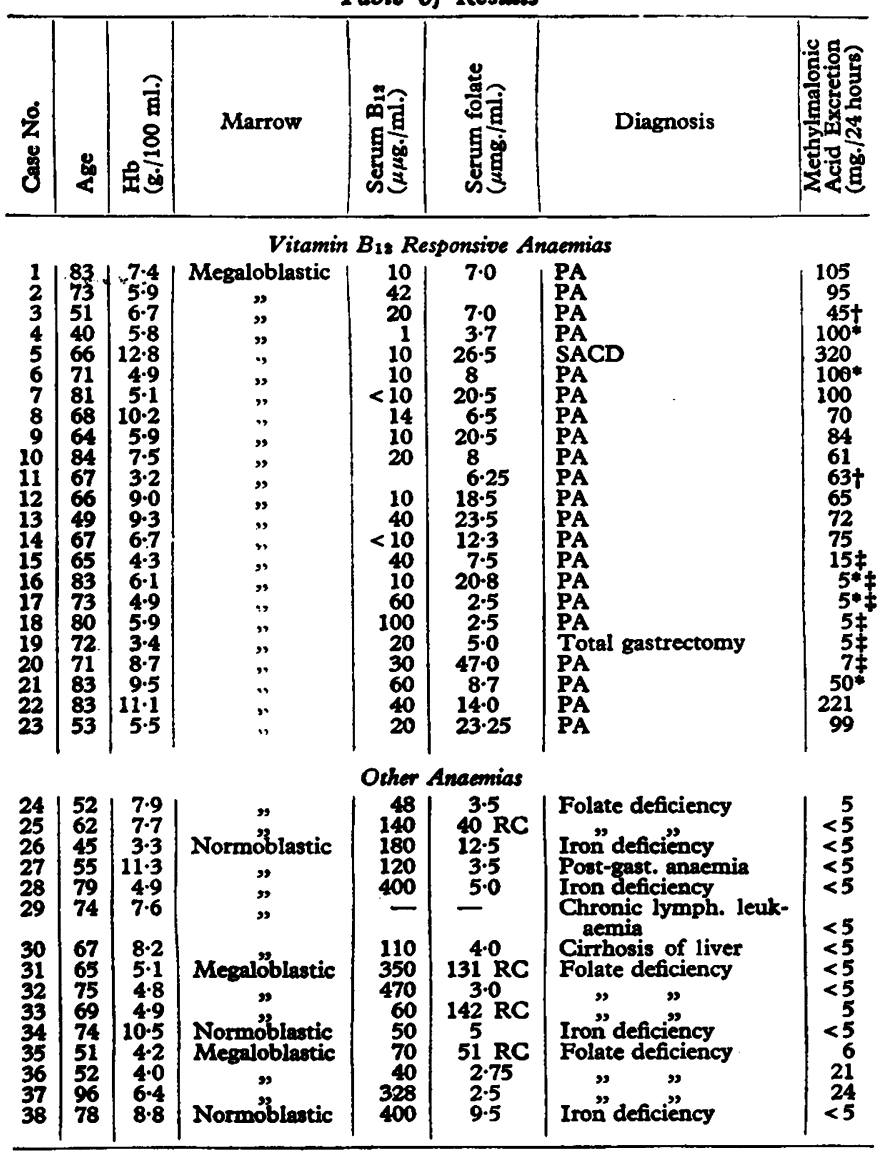

No valine loading.

in the 24 hours following vitamin $B_{18}$ injection. \# Valine given and urine collection started at least 24 hours after administration of vitamin Bis. RC $=$ Red cell folate level. PA
combined depeneration of the cord.

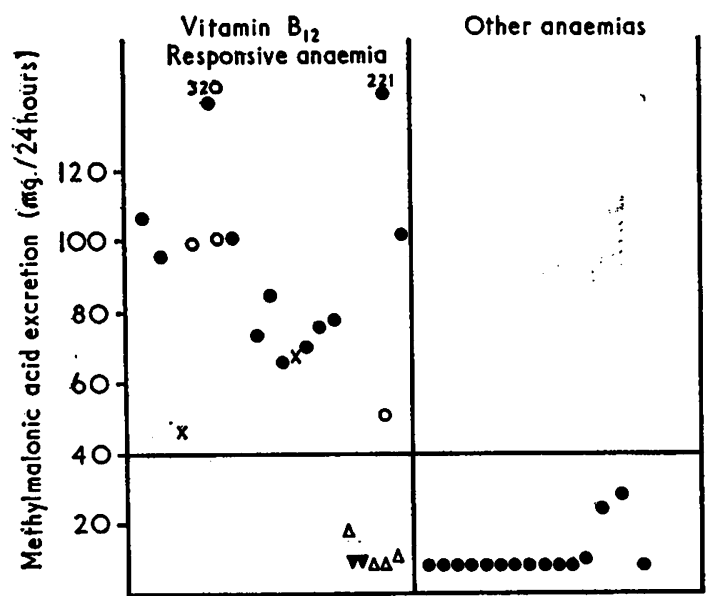

- Valine lood

- Without valine lood

$x$ Urine collected within 24 hours of vitamin $B_{12}$ therapy

$\Delta$ Urine collected more than 24 hours ofter $B_{12}$ therapy

- Urine collected more than 24 hours ofter

Patients with Other Anaemias.-This group consists of 15 patients with a variety of disorders, which have been divided into two groups. Group 1: those with a megaloblastic anaemia and evidence of folate deficiency (eight cases). In these the serum vitamin $B_{12}$ levels varied between 48 and $470 \mu \mu \mathrm{g} . / \mathrm{ml}$. They were all given valine, and urine was collected before therapy, and in each case the 24-hour excretion of methyl-

malonic acid was below $25 \mathrm{mg} . / 24$ hours (see Table and Chart). Five patients who had a low serum vitamin $B_{12}$ level but did not respond to vitamin $B_{12}$ therapy all had methylmalonic acid levels below $25 \mathrm{mg} . / 24$ hours. This suggests that the methylmalonic acid excretion is not related to the serum vitamin $B_{12}$ level, but is increased only where a true vitamin $B_{12}$ deficiency exists. Group 2 consisted of seven anaemic patients who had normoblastic erythropoiesis. The level of methylmalonic acid excretion following the valine loading was never higher than $5 \mathrm{mg} . / 24$ hours.

\section{Discussion}

In this series an increased excretion of methylmalonic acid was found only in vitamin $B_{12}$ deficient conditions; this agrees with the findings of Cox and White (1962) and Barness et al. (1963). It is of interest that the low serum vitamin $B_{12}$ levels associated with folate deficiency do not lead to an increased excretion of methylmalonic acid. One patient has presented on two occasions in six years with a severe megaloblastic anaemia responding to folic acid but not to vitamin $B_{12}$ therapy. On each occasion there was a low serum vitamin $B_{12}$ level but she did not have a raised level of methylmalonic acid in the urine before treatment.

The highest excretion of methylmalonic acid found in this series was in a patient with subacute combined degeneration of the-cord and no significant anaemia. Gompertz et al. (1967) found the highest levels of methylmalonic acid excretion in a patient with cerebral involvement.

The estimation of methylmalonic acid in urine provides a rapid means of confirming the diagnosis of vitamin $B_{12}$ deficiency. The estimation takes one and a half hours and $95 \%$ recovery can be achieved. The technique used is relatively simple to perform in a routine laboratory. By administering a valine load borderline levels were avoided, and the procedure increases the value of this estimation as a routine diagnostic test. The use of valine does not prevent the rapid fall of methylmalonic acid in the urine after treatment with vitamin $B_{12}$, so that this test is of no value if the urine is collected more than 24 hours after therapy has been instituted. During the 24-hour period following therapy, raised levels were found in two cases, but were in the lower part of our abnormal range. The test should therefore be used before therapy begins.

We have not yet confirmed whether 24-hour specimens are essential as stated by Kahn et al. (1965), who found that the excretion is not constant throughout the day. It may be possible to collect six-hour samples following valine administration. The reliability of this is being evaluated.

The method is valuable in the acute situation. It is often difficult clinically to say which deficiency is present, and usually vitamin $B_{12}$ therapy is begun without a definite diagnosis being established. If the patient is folate-deficient there will be a delay in effective treatment. The amount of methylmalonic acid excreted can be measured within 36 hours and specific treatment begun with less delay.

Though the estimation of methylmalonic aciduria with this method is most useful in situations where rapid answers are required, it may also replace vitamin $B_{12}$ assay in smaller laboratories with limited time and facilities.

We would like to thank the physicians and surgeons of the Charing Cross Hospital Group who kindly allowed us to carry out these studies on their patients.

\section{REFERENCES}

Barness, L. A., Young, D., Mellman, W. J., Kahn, S. B., and Williams, w. I. (1963). New Engl. F. Med., 268, 144.

Bashir, H. V., Hinterberger, H., and Jones, B. P. (1966). Brit. J. Haemat., 12, 704.

Cox, E. V., and White, A. M. (1962). Lancet, 2, 853.

Gompertz," D., Jones, J. H., and Knowles, J. P. (1967). Lancet, 1, 424. Green, A. (1968). \%. clin. Path., 21, 221.

Kahn, S. B., et al. (1965). 9. Lab. clin. Med., 66, 75.

White, A. M. (1962). Biochem. F., 84, 41P. 